\title{
The Defeat Depression Campaign
}

\section{A mid-point evaluation of its impact on general practitioners}

\author{
Ann Macaskill, Norman Macaskill and A. Nicol
}

\begin{abstract}
The Royal College of Psychiatrists lounched a five year campaign in 1992 to better inform health practitioners and the public about depression. A questionnaire survey of Sheflield general practitioners (GPs) to assess the impact of the Defeat Depresston Campaign on their knowledge and clinical management of depression was carried out in May 1994, half way through the campaign. Overall, $75 \%$ of GPs who responded indicated that the Defeat Depresetion Campaign had had little or no impact on thelr clinical practice. It would appear that at its mid-point the Defeat Depression Campaign falled to achleve its main goals in relation to educating GPs cbout depresston and its management.
\end{abstract}

The Defeat Depression Campaign was launched with the aims of "Reducing the stigma associated with depression, to assist general practitioners and other health care professionals in the recognition and treatment of depression and to increase public awareness of the extent and treatability of depression" (Vize \& Priest, 1993). The educational component of this campaign included:

(a) A consensus statement in the British Medical Journal on the diagnosis and management of depression (Paykel \& Priest, 1992).

(b) A video training package, Depression: From Recognition to Management, available from the Royal College of Psychiatrists (Priest, 1994a).

(c) A booklet on the diagnosis and management of depression, Defeat Depression written by Dr A. Wright, editor of the Royal College of General Practitoners.

(d) A laminated yellow card The Management of Depression In Primary Care which lists symptoms and provides straightforward advice and management.

Booklets and audio tapes on depression aimed at educating patients and relatives were also made available to GPs during the Defeat Depression Campaign (Priest, 1994b).

This study is a mid-point evaluation of the campaign's effects on one of its main target
populations-GPs, as no similar evaluation appears to have been carried out among them.

\section{The study}

In May 1994, all Sheffield GPs ( $n=325)$ were sent a 16-item Defeat Depression Campaign questionnaire aimed at assessing the following. (A copy of the full questionnaire is available from the senior author on request.)

(a) The degree to which GPs had been exposed to information and education on depression as a result of the campaign.

(b) The overall impact of the campaign.

(c) The aspects of the campaign which had had the greatest impact.

(d) The effect of the campaign on GPs' knowledge about depression and its management.

(e) The effect of the campaign on GPs' methods of assessment, frequency of diagnosis of depression, prescribing of antidepressants and non-pharmacological management of depression.

(f) The effect on referrals to Community Mental Health Teams and/or Practice Counsellors/Psychologists.

(g) The effect on GPs' promoting patient awareness and education about depression.

(h) The effect on GP trainers' approach to teaching about depression.

\section{Results}

One hundred and forty-seven completed questionnaires were returned giving a $45 \%$ response rate. Of this sample, 101 GPs (69\%) indicated that they had been aware of articles, papers or correspondence in medical literature on the Defeat Depression Campaign over the first 18 months of the campaign. Ninety-four GPs (64\%) had been invited to a local educational meeting 
Table 1. Summary of impact of the Defeat Depression campaign

\begin{tabular}{lc}
\hline & $\begin{array}{c}\text { General practitioners } \\
\mathbf{n}(\%)\end{array}$ \\
\hline 'Uttlie' or 'no' impact overall & $110(75)$ \\
Increased level of knowledge & $36(25)$ \\
Changes in assessment of depression & $22(15)$ \\
Increased frequency of diagnosis of depression & $25(17)$ \\
Changes in prescribing antidepressants & $27(19)$ \\
Increase referrals to psychologists/counsellors & $16(24)$ \\
Increased use of CPNs in Mental Health teams & $10(7)$ \\
Overall increase in counselling referrals & $23(18)$ \\
Increase in counselling by GPs & $5(3)$ \\
Increase in displays of information in surgeries & $25(57)$ \\
Increase in giving out booklets/audio tapes & $16(59)$ \\
Change in teaching by trainers & $3(13)$ \\
\hline
\end{tabular}

on clinical aspects of depression during these 18 months.

\section{Overall impact of the Defeat Depression Campaign}

This study showed that of the 36 GPs who found an increase in their knowledge of depression, only $24(16 \%)$ actually felt they had increased their levels of knowledge in a way which would change their practice in terms of diagnosis and treatment; while the remaining 12 GPs felt that it confirmed the adequacy of their current practice. Of those GPs with changed practice in assessment and frequency of diagnosis, they were now using a more systematic approach to eliciting symptoms of depression and were more likely to consider depression as a possible diagnosis. The changes in prescribing of antidepressants involved more use of SSRIs in preference to tricyclics, using higher doses $(4 \%)$, more frequently prescribing $(6 \%)$ and prescribing for longer periods during each episode of depression (see Table 1).

\section{Discussion}

This survey indicates that the Defeat Depression Campaign has had a very limited impact on the level of knowledge and clinical practice of most GPs, with $75 \%$ indicating that the campaign had little or no effect. This failure to make a significant impact cannot be ascribed to a failure of the campaign to reach most GPs; $66-69 \%$ indicated that they had received information or educational material, or had been aware of articles or papers in the medical literature about the Defeat Depression Campaign.

The failure of the campaign to impinge more significantly on the practices of GPs is com- pounded by its failure to affect the education offered by their trainers. Of the 23 trainers responding to the survey, $20(87 \%)$ indicated that the campaign had not altered their approach to teaching GP trainees about the diagnosis and management of depression. Given that one of the reasons for the campaign was the high level of depression undiagnosed by GPs, this is a particularly worrying finding. It is essential that GPs are better informed about depression during their training.

The results of this survey are disappointing, indicating that at its mid-point the Defeat Depression Campaign was not particularly successful in achieving its main aims with GPs. There is a need to replicate this study in other cities and rural areas to determine if the findings in the current survey are representative of GPs across the country.

The low overall impact of the campaign is mirrored in the specific responses to effects on knowledge, assessment, drug treatment and psychological management which all showed low rates of changes, none being greater than $25 \%$ and most being considerably lower.

The most positive finding of the survey was the increase in patient education via leaflets and audio tapes. Although, while the percentage usage was high (57\%) overall a disappointingly small number of GPs, around $50 \%$, provide educational information about depression for their patients. The Defeat Depression Campaign appears to have been well organised and to have provided high quality educational material to GPs, yet the lack of a more significant impact needs to be explained.

The 'comments' section of the questionnaire sheds some light on this. Many GPs in the survey complained of information overload with multiple competing demands for their attention. Some indicated that the campaign appeared 'low key and failed to stand out and attract their 
attention. Some $32 \%$ of GPs already felt confident in their diagnosis and management of depression so minimising the impact of the Defeat Depression Campaign. The implications of this appeared to be that they ignored the material being targeted at them. Some of this group may in fact be extremely competent at diagnosing and treating depression but it is unlikely to be true of all of them.

The results of this study suggest that to raise awareness of depression among GPs the group of GP trainers needs to be targeted specifically given their significant position of influence on future practitioners and the low impact the campaign was shown to have had on them.

This was, however, a relatively small sample encompassing only one city and with only $45 \%$ of GPs responding. In addition a questionnaire does limit the kind of response which can be recorded and more subtle changes in GP knowledge and treatment practices may have been missed.

\section{References}

PAYKel, E. S. \& PRIEST, R. G. (1992) Recognition and management of depression in general practice: Consensus Statement. British Medical Joumal, 305. 1198-1202.

PRIEST, R. G. (1994a) Improving the management and knowledge of depression. British Journal of Psychiatry. 164, 285-187.

- (1994b) Defeat Depression Campaign (letter)Psychiatric Bulletin, 18, 432-433.

VIZE, C. M. \& PRIEST, R. G. (1993) Defeat Depression Campaign: attitudes to depression. Psychiatric Bulletin, 17, 573-574.

*Dr Ann Macaskill, Principal Lecturer in Health Psychology, Health Research Institute, Sheffield Hallam University, Collegiate Campus, Sheffield S10 2BP, Dr Norman D. Macaskill, Consultant Psychotherapist, Psychotherapy Department, Nottingham; and Dr A. Nicol, Senior Registrar in Psychiatry, Whiteley Wood Clinic, Sheffield

*Correspondence 